\title{
DEWA RUCI: SEBUAH ALTERNATIF SISTEM PENDIDIKAN
}

\author{
Siti Isnaniah
}

Email: isnaoke_niah@yahoo.com

Jurusan Dakwah dan Komunikasi STAIN Surakarta

Alamat Korespondensi: Mendungsari Rt 02/III, Bulurejo, Gondangrejo, Karanganyar, Jawa Tengah 57773

\begin{abstract}
The Dewa Ruci story tells us about Bratasena's travel in finding the true life. On the way, he should obey to Durna, who is a controversial teacher and as the enemy of the Pandawa family. Along his journey, Bratasena encounters many obstacles and it makes him find out his mature, and deeper understanding of himself. Finally, Bratasena succeeds in discovering the life perfections. It is due to his loyalty to teacher, institution, and his profession. This story could be used as a reference in the education system. As an education instrument, wayang purwa offers values on teaching that could be applied by teachers. Nowadays, the puppet shows can be presented in various innovations. One of the innovation forms of Dewa Ruci Purwa Puppet played by Ki Manteb Soedharsono is packaged in the form of video compact disc including the Indonesian and English text. Dewa Ruci Purwa Puppet gives benefit to students, teachers, parents, societies, also government. Students can learn the story of Bratasena in finding the true life, the parents can learn from Dewi Kunthi the way she educates her children, and the government can improve education system by applying the values implied in the story. The education system can imitate Bratasena's independence in finding science to get the best achievement by maintaining the motivations and the instruction of the teacher.
\end{abstract}

\section{Kata Kunci}

Dewa Ruci, Sistem Pendidikan, Nilai

\section{Pendahuluan}

Wayang merupakan budaya bangsa yang telah diakui oleh Unesco (organisasi pendidikan, ilmu pengetahuan dan kebudayaan PBB) sejak 7 November 2003 sebagai World Master Piece of Oral and Intangible Heritage of Humanity. Bahkan sebuah pergelaran besar seni budaya wayang Indonesia bertajuk Wayang Shadow Puppet Theatre of Indonesia telah dipentaskan di markas PBB, Jenewa, pada tanggal 15 April 2008. Selain itu, wayang juga merupakan ikon dalam World Heritage Cities (WHC), sebuah konferensi kelas dunia yang diadakan oleh OWHC (Organization of World Heritage Cities), sebuah organisasi di bawah Unesco. WHC telah diadakan di Surakarta pada tanggal 25-28 Oktober 2008 dan untuk menyambut acara tersebut, Surakarta memiki slogan Let's Go to Solo The Spirit of Java. Sebuah kebanggaan tersendiri bagi Surakarta karena dipercaya oleh PBB untuk mengembangkan budaya daerah yang salah satunya adalah wayang.

Kebanggaan itu rasanya tidak akan bertahan lama tatkala kita mendapati banyak generasi muda sekarang yang tidak suka dengan budayanya sendiri. Di antara mereka ada yang lebih suka mengekor budaya barat yang belum tentu bermanfaat dan memandang sebelah mata terhadap budaya daerah. Kebanyakan mereka beranggapan bahwa budaya daerah itu kuno dan ketinggalan zaman. Misalnya wayang, akan jarang sekali kita jumpai generasi muda yang bisa memainkan wayang atau melihat wayang karena memang selama ini wayang biasanya dipentaskan semalaman suntuk sehingga membuat generasi muda merasa bosan. Oleh sebab itu hadirnya pakeliran padat, pementasan wayang yang disajikan dalam waktu singkat, merupakan sebuah inovasi untuk mengembangkan budaya daerah tanpa kehilangan pakemnya.

Dewa Ruci merupakan salah satu ikon cerita yang dipentaskan dengan pakeliran padat. Cerita tersebut bahkan telah dituangkan dalam bentuk film dalam VCD dengan durasi satu jam. Pementasan tersebut didalangi oleh dalang setan, Ki Manteb Soedharsono, yang sudah begitu lihai dalam mendalang. Penulis tertarik dengan cerita Dewa Ruci karena cerita tersebut mengandung ajaran yang sangat mulia terutama menceritakan 
kegigihan seorang murid yang bernama Bratasena dalam mencari ilmu. Penulis juga tertarik dengan dalang Ki Manteb Soedharsono karena selain terkenal sebagai dalang setan yang sangat mahir, Ki Manteb telah diakui secara internasional oleh Unesco PBB karena ia telah dipercaya oleh PBB sebagai dalang berkualitas sehingga layak menerima Unesco Award pada bulan April 2004 (Solopos, 8 April 2004).

Dengan inovasi pakeliran padat, seperti pementasan wayang dengan durasi singkat (satu jam) dan dikemas dalam bentuk VCD, hal itu akan sangat mudah dipelajari oleh generasi penerus dan dirasa juga menarik. Selama ini mereka kurang suka dengan wayang karena salah satu sebabnya adalah media penyampaiannya kurang menarik. Oleh sebab itu, tulisan ini bertujuan ingin mengenalkan ajaran-ajaran wayang yang diangkat dari cerita wayang lakon Dewa Ruci versi pakeliran padat dengan dalang Ki Manteb Soedharsono, yang bisa dijadikan sebagai kontribusi terhadap sistem pendidikan di Indonesia.

Seperti diketahui bahwa pendidikan merupakan kebutuhan primer dalam hidup. Oleh sebab itu, berbagai kebijakan telah digulirkan untuk meningkatkan kualitas pendidikan di Indonesia. Berbagai kebijakan tersebut telah menimbulkan pro-kontra di berbagai pihak, dan ternyata sangat berdampak terhadap kualitas pendidikan di Indonesia hingga detik ini.

Lengsernya mantan Presiden Soeharto dengan orde barunya telah meninggalkan berbagai "warisan" yang harus digarap oleh pemerintah selanjutnya. Kebijakan di era orde baru (orba) telah dibangun dengan metodenya sendiri sehingga menghasilkan kebijakan bahwa pendidikan bukan prioritas utama dalam pembangunan nasional karena yang paling diprioritaskan saat itu adalah sektor ekonomi dengan filsafat kapitalismenya sehingga pemerataan terabaikan dan sumber daya manusia sangat tertinggal, serta kita kalah dengan Barat hampir dalam semua sektor kehidupan.

Di era reformasi pun, pendidikan juga belum mendapat perhatian intens dari pemerintah. Hal tersebut bisa terbukti dengan timbulnya berbagai permasalahan pendidikan di Indonesia, di antaranya sistem pendidikan yang bobrok, kesempatan dan kualitas pendidikan yang belum merata, komersialisasi pendidikan, saranaprasarana memprihatinkan, kualitas sumber daya manusia yang rendah termasuk kualitas tenaga kependidikan (guru), kurikulum yang tambal-sulam, KKN yang susah diberantas, dan belum terealisasinya anggaran pendidikan $20 \%$ dari APBN/ APBD.

Begitu banyaknya permasalahan di dunia pendidikan telah berimbas pula terhadap berbagai bidang kehidupan, salah satunya terhadap sastra daerah yang juga merupakan pembelajaran. Dalam dunia pewayangan, Dewa Ruci merupakan sastra daerah yang kebanyakan generasi muda sudah melupakannya, padahal mengandung niali-nilai yang adiluhung.

Di dalam sastra, terdapat unsur-unsur yang sangat penting bagi kehidupan, di antaranya unsur-unsur kemanusiaan, keindahan, pendidikan, kereligiusan, dll. Oleh sebab itu, sastra termasuk sastra daerah perlu diajarkan kepada siswa melalui pendidikan.

Banyak suara di lapangan yang menyebutkan bahwa pembelajaran sastra kita selama ini belum maksimal karena masih mengalami berbagai permasalahan, di antaranya: pertama, masih rendahnya minat baca siswa dan guru terhadap sastra sehingga kompetensi dan pengetahuan mereka tentang sastra masih kurang. Kedua, minimnya buku-buku karya sastra yang bisa diapresiasi guru dan siswa di sekolah. Ketiga, pembelajaran sastra kurang diminati oleh siswa, sastra belum ditempatkan dalam kategori mata pelajaran yang diperhitungkan. Keempat, situasi dan kondisi sekolah kurang menunjang pembelajaran dan apresiasi sastra. Kelima, evaluasi tidak sesuai dengan tuntutan kurikulum karena lebih menitikberatkan pada ranah kognitif daripada ranah afektif dan psikomotorik. Hal tersebut bisa dilihat dari pelaksanaan UNAS dan UN yang masih menjadi perhatian utama tiap sekolah karena menyangkut reputasi di masyarakat.

Pembelajaran sastra memang selalu menarik diperhatikan. Di era globalisasi dengan semakin menjamurnya budaya dan saling kontak antarnegara akan menimbulkan kompetisi dengan sastra asing yang semakin luas penyebarannya. Oleh sebab itu, sastra daerah dan Indonesia harus mampu menunjukkan jati diri dan eksistensi bangsa di mata dunia, serta harus mampu menjadi media transformasi nilai-nilai budaya modern yang berkembang selaras dengan ilmu pengetahuan, teknologi, dan seni (Ipteks).

Agar semua tuntutan di atas dapat terwujud, kita harus mampu mengeksplorasi dan mengeksploitasi sastra daerah dan Indonesia untuk mengungkapkan nilai-nilai yang sangat bermanfaat bagi kehidupan, seperti kemanusiaan, keindahan, keluhuran budaya dan identitas bangsa, religius, modernitas, dll. Dengan 
demikian, sastra daerah dan Indonesia dapat memiliki eksistensi dan dapat berkompetisi dengan karya-karya modern lainnya.

Dewa Ruci merupakan salah satu karya sastra daerah yang masih tetap hidup berdampingan dengan karya-karya sastra lain di Indonesia. Dewa Ruci diambil dari cerita wayang purwa yang merupakan salah satu karya sastra Jawa yang adiluhung dan isinya dapat dijadikan sebagai bekal dalam kehidupan. Cerita wayang purwa lakon Dewa Ruci banyak mengajarkan nilai-nilai hidup dan yang paling penting dari cerita tersebut adalah kegigihan seorang murid dalam berprinsip untuk terus menuntut ilmu sampai berhasil. Sifat idealisme itulah yang membuat cerita Dewa Ruci lebih menarik untuk dikaji. Hal tersebut sesuai dengan pendapat Rahayu Supanggah (2002: 17-18) bahwa nilainilai edukatif dalam cerita wayang purwa lakon Dewa Ruci meliputi:

Pertama, pentingnya nilai ketekunan, kegigihan, keyakinan, dan kepercayaan seseorang terhadap pilihan ilmu pengetahuan (kesenian), profesi, instansi pendidikan dan guru hanya merupakan fasilitator dan sarana untuk mencapai tujuan pendidikan. Tanpa adanya keyakinan dan kepercayaan terhadap ketiga komponen tersebut, seseorang tidak akan mungkin berhasil meraih cita-citanya. Begitu pula Columbus, ia selalu yakin untuk terus berjalan ke timur sehingga akhirnya ia menemukan Kuba.

Kedua, bekerja dengan sungguh-sungguh dan serius, berani mengambil segala risiko terhadap langkah yang telah ditempuh dalam menuntut ilmu sampai berhasil.

Cerita lakon Dewa Ruci diambil dari cerita Mahabarata yang sejak dahulu sampai sekarang masih digemari oleh masyarakat khususnya masyarakat Jawa. Oleh karena itu, cerita Mahabarata (lakon Dewa Ruci) dapat diambil nilai-nilai edukatifnya yang memiliki relevansi dengan zaman sekarang. Karena wayang berfungsi sebagai sarana pendidikan, nilai-nilai yang terkandung dalam wayang itu sangat baik untuk ditanamkan kepada generasi muda.

Berdasarkan penjelasan di atas, tulisan ini akan memfokuskan pembahasan pada nilai-nilai yang terkandung dalam cerita Dewa Ruci yang bisa dijadikan sebagai kontribusi terhadap sistem pendidikan di Indonesia.

\section{Sastra Lisan dan Formulanya}

Sastra merupakan wilayah yang bisa diredefinisikan karena sampai sekarang banyak ahli yang secara ontologis belum bisa merumuskan batasan yang tepat tentang sastra itu sendiri. Konsep sastra selalu muncul tetapi sering berakhir dengan kesimpulan yang gagal, belum bisa menjawab pertanyaan tersebut. Para ahli sastra biasanya memberikan batasanbatasan pada ranah tertentu sehingga batasanbatasan tersebut masih belum jelas, bahkan bisa menimbulkan polemik.

Zainuddin Fananie (1982) memberikan batasan bahwa suatu teks sastra setidaknya harus mengandung tiga aspek utama, di antaranya decore (memberikan sesuatu kepada pembaca), delectare (memberikan kenikmatan melalui unsur estetik), dan movere (mampu menggerakkan kreativitas pembaca). Jadi, seni (sastra) memang perlu bersifat utile dan dulce (bermanfaat dan manis). Sementara itu, Abrams memberikan batasan sastra pada pendekatan objektif (menitikberatkan pada karya itu sendiri), ekspresif (menitikberatkan pada penulis), mimetik (berhubungan dengan kesemestaan/ universe), dan pragmatik (menitikberatkan pada pembaca). Kerangka (frame work) tersebut bisa dijadikan alternatif untuk memahami dan meneliti situasi sastra secara menyeluruh (the total situation of a work of art).

Batasan konsep tersebut bersifat dinamis, seiring dengan perkembangan zaman, terutama perkembangan teori, kritik, dan sejarah sastra. Tetapi, setidak-tidaknya batasan sastra tersebut dapat dikatakan sebagai konvensi sastra, walaupun memang tidak tertulis. Batasan konsep sastra tentunya merupakan pemikiran, sikap, dan pandangan para pengarangnya sehingga antara pengarang yang satu dengan lainnya memiliki ciri khas yang berbeda dalam menciptakan karya sastra sehingga perbedaaan tersebut dapat melahirkan berbagai metode, teori, dan teknik penelitian sastra yang biasanya berkembang dalam satuan waktu tertentu, dan sudah bukan rahasia lagi hadirnya sebuah pendekatan sastra turut menjadi tren dan mewarnai dunia kesastraan Indonesia.

Salah satu tren yang turut mewarnai dunia kesastraan Indonesia adalah sastra lisan. Menurut Chairil Effendy, sastra lisan merupakan fakta mental yang menggambarkan mimpimimpi, cita-cita, aspirasi, keinginan, harapan, keluh-kesah, dan sebagainya yang kesemuanya merupakan sistem pengetahuan masyarakat. Masyarakat pemiliknya mentransmisikan sastra lisan dari waktu ke waktu, dari generasi ke generasi agar kandungan sastra lisan itu terinternalisasikan sebagai pedoman bagi hidup mereka dalam menyikapi tantangan kehidupan. 
Atmazaki (1990: 82) menyatakan bahwa ada beberapa hal penting yang harus diperhatikan dalam sastra lisan, yaitu sesuai dengan namanya sastra lisan adalah jenis karya sastra yang disampaikan secara lisan dari mulut juru cerita. Sebagai konsekuensinya, juru cerita akan selalu menyesuaikan diri dengan situasi dan kondisi penikmatnya. Situasi penikmat menyebabkan perbedaan cara penyampaian sastra lisan, yaitu dengan menambah atau mengurangi, bahkan sering mengubah sehingga tidak mengherankan jika terjadi sejumlah variasi terhadap suatu cerita. Juru cerita selalu berusaha menarik perhatian penikmatnya meskipun ia harus berimprovisasi mengubah cerita.

Improvisasi tersebut tidak bisa terlepas sama sekali dengan tradisi kesusastraan yang sedang berlaku karena juru cerita selalu menggunakan formula-formula yang telah ada dalam sebuah tradisi (Ong, 1982: 19). Formula tersebut digunakan untuk mengungkapkan tokoh, peristiwa yang berlangsung dalam cerita, serta mengidentifikasi ruang dan waktu (Lord, 1976: 34). Jadi, dalam setiap pertunjukan selalu terjadi penciptaan. Hal tersebut yang sering terjadi dalam pakeliran wayang kulit purwa, salah satunya adalah wayang kulit purwa lakon Dewa Ruci yang didalangi oleh Ki Manteb Soedharsono. Dengan lakon yang sama dalam waktu dan tempat yang berbeda maka hasilnya akan berbeda pula. Dengan demikian, setiap kali dalang menyajikan lakon, setiap kali itu pula ia menciptakan walaupun dengan lakon yang sama.

Dalam dunia pakeliran wayang kulit purwa dikenal lakon baku (pakem) dan tidak baku (carangan). Meskipun demikian, perubahan sering terjadi sesuai dengan tuntutan zaman. Singgih Wibisono (dalam Yohanes Brefeur Rahno Triyogo dan Kuntara Wiryamartana, 2001) menyatakan bahwa perubahan itu sering tidak bisa dihindari karena tuntutan zaman dan terjadinya pergeseran-pergeseran nilai-nilai budaya. Salah satu lakon dalam pakeliran wayang kulit purwa yang mengalami inovasi dan perubahan adalah wayang kulit purwa lakon Dewa Ruci yang didalangi oleh Ki Manteb Soedharsono yang dibawakan dengan durasi satu jam dalam kemasan VCD (tidak semalaman suntuk). Hal tersebut dimaksudkan untuk mengurangi kejemuan penonton terutama generasi muda (siswa) sehingga bisa diajarkan dalam pembelajaran. Bahkan sebagai sastra lisan, pakeliran wayang kulit purwa bisa dibawakan dengan bahasa Inggris, mengingat wayang sudah diakui Unesco sebagai World Master Piece of Oral and Intangible Heritage of Humanity.

\section{Wayang sebagai Fenomena Pendidikan}

Munculnya wayang dapat digunakan oleh siapa saja dan dapat digunakan sebagai sarana apapun. Pertunjukan wayang purwa dapat digunakan dalam pembinaan moral, menyampaikan pesanpesan tertentu yang mendidik, dan dapat memotivasi semangat kemasyarakatan. Pertunjukan wayang purwa merupakan budaya masyarakat Jawa yang berkualitas tinggi dan kompleks karena didalamnya mencakup berbagai bentuk seni yang menyatu yaitu seni sastra, bahasa, drama, musik, tari, seni rupa, dan sebagainya. Dalam pertunjukannya bernilai adiluhung karena tidak sekedar berfungsi sebagai tontonan "hiburan", tetapi juga sebagai seni budaya tuntunan "ajaran hidup: pendidikan, serta tataning ngaurip "aturan hidup". Hadirnya wayang dapat dijadikan sebagai media pendidikan terutama dalam pembinaan moral bagi generasi muda.

\section{Dewa Ruci: Kajian Edukatif}

\section{Hakikat Nilai Edukatif}

Lukman Ali dalam Kamus Besar Bahasa Indonesia, (1999: 690) menyatakan bahwa nilai diartikan sebagai sifat-sifat (hal-hal) yang penting atau berguna bagi kemanusiaan. Dalam bahasa Inggris nilai berarti value yang berasal dari istilah latin valere yang berarti berguna, mampu akan, berdaya, berlaku, dan kuat. Kaitannya dengan yang dibahas disini, arti yang lebih tepat adalah berguna. Nilai diartikan sebagai sesuatu yang dipandang baik, disukai, paling benar, dan dapat diterima oleh perorangan atau kelompok masyarakat.

Banyak ahli yang memberikan batasan mengenai pengertian nilai. Pendapat-pendapat tersebut pada intinya sama dalam arti terjadi kesepakatan bahwa nilai selalu berkaitan dengan kebaikan, kebajikan, dan keluhuran. Nilai merupakan sesuatu yang dihargai, selalu dijunjung tinggi, serta selalu dikejar manusia dalam memperoleh kebahagiaan hidup. Manusia dapat merasakan kepuasan dengan nilai, baik kepuasan lahiriah maupun batiniah. Dengan nilai manusia akan menjadi manusia yang sebenarnya.

Nilai merupakan sesuatu yang abstrak, tetapi secara fungsional mempunyai ciri yang mampu membedakan satu dengan lainnya. Suatu nilai jika dihayati akan berpengaruh terhadap cara berpikir, cara bersikap, maupun cara bertindak seseorang dalam mencapai tujuan hidupnya. Nilai sebagai ukuran selalu menjadi pertimbangan dalam mencapai cita-cita yang diinginkan untuk menentukan kebenaran dan keadilan. Alasanalasan religius, etika, estetika, dan intelektual dijadikan dasar yang intinya bersumber pada 
ajaran agama, logika, maupun norma yang berlaku dalam suatu masyarakat.

Berdasarkan uraian di atas, nilai-nilai itu ternyata identik dengan sesuatu yang baik dan benar. Pendidikan yang paling efektif sebenarnya adalah lewat keteladanan, tokoh-tokoh karismatik harus mampu mengendalikan diri dan mencontohkan pola pikir serta perilaku positif kepada lingkungannya. Propaganda tentang moral, etika, dan dalil-dalil saja tidak akan banyak membantu pengembangan kepribadian, kecuali dalam bentuk keteladanan (Maria Ardhie, 2003).

John M. Echols dan Hassan Shadily (1982:207) mengatakan bahwa education berarti pendidikan, sedangkan orang yang melakukan pendidikan disebut educator. Sedangkan menurut Lukman Ali dalam Kamus Besar Bahasa Indonesia (1999:232) pendidikan diartikan sebagai proses pengubahan sikap dan tata laku seseorang atau kelompok orang dalam usaha mendewasakan manusia melalui upaya pengajaran dan pelatihan; proses, perbuatan, cara mendidik.

Sastra, pendidikan, dan tata nilai merupakan hal yang tidak dapat dipisahkan. Sastra pada dasarnya merupakan refleksi kehidupan. Kaitannya dengan pendidikan, sastra dan tata nilai kehidupan merupakan dua fenomena sosial yang saling melengkapi. Pendidikan sebagai usaha untuk membentuk nilai hidup, sikap hidup, dan pribadi seseorang.

Karya sastra yang tercipta terkadang mengungkapkan realitas kehidupan dengan permasalahan yang ada. Wayang merupakan karya sastra Jawa, bukan sekedar sebagai sarana hiburan, tetapi juga sebagai media komunikasi, media penyuluhan, dan media pendidikan (Bagus Haryono dan Mahendra Wijaya, 2001)

Hal senada juga diungkapkan oleh Suminto A. Sayuti dalam Jurnal Bahasa dan Sastra Indonesia Menuju Peran Transformasi Sosial Budaya Abad XXI, 2001 bahwa sastra dapat dijadikan sebagai media transformasi edukatif, kultural, dan keluhuran budi manusia.

Sudaryanto (Makalah Studi Banding HIMA PBSI UNY dan HIMPROBSI FKIP UNS, 8 Mei 2003) menyatakan bahwa sastra sebagai sarana untuk mengajarkan nilai-nilai moral. Hal senada dikemukakan oleh Haz, bahwa sastra Jawa bisa memperhalus budi pekerti siswa dan bisa diterapkan dalam kehidupan bermasyarakat, berbangsa, dan bernegara, serta menjunjung tinggi budaya dan dan sastra Jawa yang penuh dengan norma budi pekerti; namun kesemuanya itu perlu perhatian pemerintah terkait seperti
Dinas Pendidikan dan Kebudayaan, serta Pemda setempat.

Wayang purwa lakon Dewa Ruci sebagai karya sastra Jawa baik secara tersirat maupun secara tersurat mengandung sisi keteladanan yang edukatif. Wayang purwa merupakan warisan budaya dunia yang sangat besar manfaatnya terutama dari sisi keteladanan tokoh-tokohnya. Hal ini terbukti dari pernyataan, "pakeliran wayang purwa berhasil meraih penghargaan tertinggi adab dunia bidang pendidikan dan kebudayaan, Unesco Awards."(Solopos, 8 April 2004).

Berdasarkan uraian di atas dapat disimpulkan bahwa Pendidikan merupakan suatu usaha, kegiatan, maupun pengaruh yang diberikan secara sadar dan terencana dengan memberikan bimbingan dan tuntunan agar manusia dapat melaksanakan tugas hidupnya. Sebagai bekal maka diperkenalkan nilai hidup seperti nilai edukatif.

\section{Sinopsis Cerita Wayang Purwa Lakon Dewa Ruci}

Pada awalnya Bratasena sangat merasa sedih karena memikirkan nasib ayahnya "Pandu" yang tidak jelas nasibnya karena dimasukkan ke dalam kawah Candradimuka sehingga membuatnya ingin mencari ilmu kesempurnaan hidup dengan cara berguru kepada Durna. Keinginan Bratasena diterima oleh Durna tetapi dengan syarat bahwa Bratasena harus mencari Kayu Gung Susuhing Angin yang berada di Gunung Candramuka di hutan Tikbrasara. Mendengar hal tersebut, Bratasena langsung percaya dan minta doa restu Durna untuk mencarinya meskipun banyak sekali rintangannya. Bratasena tidak mengetahui siasat yang direncanakan oleh Durna dan para Kurawa karena ia percaya bahwa guru itu selalu mengajarkan kebaikan.

Kepergian Bratasena ke Gunung Candramuka diikuti oleh Dursasana dan para Kurawa atas perintah Sengkuni. Sesampainya di Gunung Candramuka di hutan Tikbrasara, Bratasena dihadang oleh dua raksasa yang sangat menakutkan yaitu Rukmuka dan Rukmakala sehingga terjadilah peperangan yang dahsyat antara Bratasena dengan Rukmuka dan Rukmakala tetapi akhirnya dapat dikalahkan oleh Bratasena. Akhirnya kedua raksasa tersebut berubah menjadi Hyang Indra dan Hyang Bayu. Bratasena memang sengaja duuji kesungguhannya dalam menuntut ilmu oleh Hyang Indra dan Hyang Bayu. Sebagai ucapan terimakasih, Hyang Indra dan Hyang Bayu memberi cincin kepada Bratasena yang bernama 
Sesotya Mustika Manik Candrama. Cincin tersebut merupakan ikatan yang dapat mendekatkan diri kepada Tuhan dan gunanya adalah Bratasena dapat mengarungi dasar samudera. Hyang Indra dan Hyang Bayu juga menjelaskan tentang Kayu Gung Susuhing Angin kepada Bratasena bahwa Kayu Gung Susuhing Angin artinya niat yang besar akan terlaksana jika disertai dengan pengaturan nafas, heningnya pikiran, mengendapnya panca indera, dan tenangnya rasa. Setelah mendengar penjelasan tersebut, Bratasena merasa belum puas sehingga disuruh Hyang Indra dan Hyang Bayu menemui kembali Durna.

Bratasena menemui Durna dan memintanya segera menjelaskan ilmu kesempurnaan karena Bratasena sudah berhasil memenuhi syarat seperti yang telah ditugaskan Durna yaitu menemukan Kayu Gung Susuhing Angin tetapi Durna masih mengajukan satu syarat lagi yaitu supaya Bratasena mencari Tirta Pawitra yang berada di Samudera Minangkalbu. Bratasena menyetjui syarat tersebut dan tanpa basa-basi ia segera minta doa restu Durna untuk mencarinya.

Sebelum pergi ke Samudera Minangkalbu, Bratasena kembali ke Amarta untuk meminta doa restu ibunya "Dewi Kunthi". Pada awalnya Dewi Kunthi sangat keberatan dengan keinginan Bratasena untuk pergi ke Samudera minangkalbu karena banyak rintangannya dan menjelaskan bahwa Durna itu licik tetapi Bratasena tetap teguh pada pendiriannya untuk terus maju menuntut ilmu. Akhirnya ibunya mengizinkan dan merestui serta mendoakannya agar Bratasena selamat dan tercapai cita-citanya.

Bratasena segera pergi ke Samudera Minangkalbu. Di tengah perjalanan, di Wana Sunyapringga (hutan yang berbahaya), ia dihadang oleh saudaranya Tunggal Bayu yaitu Anoman (kera berwarna putih), Jajakwreka (raksasa berwarna merah), Setubanda (gajah berwarna hijau), dan Begawan Maenaka (pendeta berpakaian serba kuning) Terjadilah peperangan antara Bratasena dengan saudara Tunggal Bayu yang akhirnya dapat dikalahkan oleh Bratasena. Serangan saudara Tunggal Bayu terhadap Bratasena sebenarnya hanya untuk menguji kesungguhan Bratasena dalam menuntut ilmu. Saudara Tunggal Bayu hanya bisa berdoa agar Bratasena selamat dan tercapai cita-citanya.

Bratasena akhirnya sampai di tepi Samudera Minangkalbu atau Laut Selatan. Laut tersebut sangat ganas, gelombang bergulung setinggi gunung, menggemuruh, mega menutupi sinar matahari, kilat menyambar, dan suara halilintar membuat hati Bratasena gentar. Sekilas Bratasena merasa takut karena ia adalah juga manusia biasa tetapi segera disingkirkan rasa takut itu dengan tekad yang kuat, taat pada perintah guru. Bratasena segera masuk ke Samudera walaupun harus mati sebagai manusia utama. Karena Bratasena mempunyai cincin Sesotya Mustika Manik Candrama, seketika samudera menjadi tenang yang menandakan bahwa Bratasena sudah bisa mengendalikan hawa nafsunya. Tiba-tiba ada ular "Nagaraja" menyambar dan melilit tubuhnya. Dengan kuku Pancanakanya, Nagaraja berhasil dikalahkan oleh Bratasena. Kemudian Bratasena bertemu Dewa Ruci dan dijelaskanlah kepada Bratasena tentang Tirta Pawitra dan ilmu kesempurnaan hidup. Kemudian Bratasena masuk ke dalam tubuh Dewa Ruci yang kecil. Pada waktu masuk ke tubuh Dewa Ruci yang dirasakan pertama kali adalah bingung karena hanya melihat awanguwung tanpa batas yang melambangkan bahwa pada tingkat pertama mencapai kesempurnaan manusia masih dalam keadaan bodoh dan bingung. Setelah mendapat petunjuk dari Dewa Ruci, Bratasena menjadi merasa terang dan sampai pada tingkat kesadaran total. Bratasenakemudian melihat cahaya empat warna: hitam yaitu cahaya yang berasal dari bahan makanan yang melambangkan angkara yang merusak, merah dari hewan yang melambangkan sumber kemarahan seperti nafsu hewan, kuning berasal dari segala sesuatu yang terbang yang melambangkan keinginan kekuasaan dan kesenangan belaka, dan putih berasal dari ikan air tawar yang melambangkan ketentraman seperti ikan di air tawar. Empat warna tersebut menggambarkan nafsu aluamah, amarah, supiah, dan muthmainah. Bratasena merasa nyaman di dalam tubuh Dewa Ruci sehingga tidak mau keluar tetapi hal itu dilarang oleh Dewa Ruci karena belum saatnnya karena masih ada tugas yang harus diselesaikan oleh Bratasena. Setelah keluar dari tubuh Dewa Ruci, Bratasena menjadi manusia suci seperti baru terlahir. Pada saat itu ia mencapai manunggaling kawula Gusti.

Akhirnya Bratasena kembali menemui gurunya "Durna" dan menggap Durna sebagai guru sejati. Sejak berusaha menuntut ilmu sampai berhasil, Bratasena tidak pernah su'udzan (berburuk sangka) pada Durna meskipun dalam Durna pernah ada benih Kurawa. Meskipun demikian Durna telah berhasil mengantarkan Bratasena pada keberhasilan.

\section{Unsur-unsur Intrinsik dalam Cerita Dewa Ruci}

(a) Bertema, perjuangan seorang murid dalam menuntut ilmu, (b) beramanat, usaha yang sungguh-sungguh pasti akan meraih keberhasilan. (c) beralur progresif (d) tokoh- 
tokoh dalam cerita wayang lakon Dewa Ruci ini meliputi tokoh Protagonis dan tokoh Antagonis. Tokoh Protagonis meliputi Bratasena, Dewi Kunthi, Dewa Ruci, Permadi-Puntadewa, Punakawan, Anoman, Hyang Indra-Hyang Bayu. Tokoh-tokoh Antagonis meliputi Durna, Sengkuni, Dursasana. Tokoh-tokoh dalam cerita wayang lakon Dewa Ruci ini meliputi: Bima/Bratasena adalah tokoh jujur dan idealis; Durna adalah guru Bima, sebagai guru ia baik karena telah memberi motivasi murid-muridnya untuk mencapai cita-cita; Dewi Kunthi adalah ibu para Pandawa. Ia adalah figur seorang ibu yang baik dan tabah dalam menghadapi kesulitan hidup. Kunthi selalu mengajarkan pada putraputranya tentang nilai-nilai kebaikan dan kebenaran; Sengkuni, orang yang tidak suka terhadap Pandawa dan selalu menghalanghalangi Bima/Bratasena dalam menuntut ilmu; Sengkuni, selalu menghalang-halangi Bima/Bratasena dalam menuntut ilmu; Dursasana, Kurawa yang tidak suka terhadap Pandawa dan selalu menghalang-halangi Bima/Bratasena dalam menuntut ilmu; Rukmuka dan Rukmakala, dua raksasa yang menyerang Bratasena di hutan Tikbrasara untuk menguji kesungguhan Bratasena dalam menuntut ilmu. Dua raksasa tersebut merupakan jelmaan dari Dewa Indra dan Dewa Bayu; Permadi dan Puntadewa, tokoh yang mempunyai perwatakan sayang, mereka adalah saudara Bratasena; Anoman, saudara Tunggal Bayu Bratasena dan ia juga mempunyai perwatakan yang baik; Punakawan, mereka terdiri dari Semar, Gareng, Petruk, dan Bagong (e) Setting meliputi Kawah Candradimuka, Gunung Candramuka, Hutan Tikbrasara, Astina, Amarta, Wana Sunyapringga, dan Laut Selatan/Samudera Minangkalbu.

\section{Nilai-nilai Edukatif dalam Cerita Dewa Ruci}

Cerita wayang purwa lakon Dewa Ruci berisi nilai-nilai edukatif. Nilai-nilai edukatif yang terdapat didalamya diambilkan dari tokohtokohnya. Perbuatan yang dilakukan oleh tokohtokoh tersebut sangat baik untuk dijadikan teladan atau panutan dalam kehidupan seharihari. Nilai-nilai edukatif dengan sendirinya merupakan akumulasi cipta, rasa, dan karsa seseorang yang diimplemetasikan dalam katakata, sikap, dan tingkah laku seseorang. Dalam aktualisasi kehidupan sehari-hari, nilai-nilai edukatif terdiri dari perbuatan baik dan jahat. Tentunya nilai-nilai yang baik kita contoh dan yang jahat kita tinggalkan. Nilai-nilai edukatif dalam cerita wayang purwa lakon Dewa Ruci antara lain:

\section{Suka menuntut ilmu dan bekerja keras}

Bratasena suka menuntut ilmu meskipun selalu mendapatkan rintangan dan godaan. Syarat yang diajukan gurunya yaitu mencari Kayu Gung Susuhing Angin dan Tirta Pawitra. Bratasena selalu mencarinya sampai berhasil jika ia benarbenar ingin mencari ilmu kesempurnaan hidup. Hal tersebut menggambarkan bahwa ilmu itu harus didapat dengan usaha sesuai dengan pendapat KGPAA Mangkunegara IV bahwa dalam serat Wedhatama (Endraswara, 2003: 108), pupuh pocung menyarankan beberapa hal sebagai berikut:

\section{Ngelmu iku kelakone kanthi laku \\ Lekase lawan kas \\ Tegese kas nyantosani \\ Setya budya pangekesedur angkara}

Terjemahan: Ngelmu itu, terlaksananya harus dengan laku (pekerti)

Dimulai dengan tekad yang bulat (niat) yang teguh sehingga akan tercapai kesentausaan dan ketenangan batin. Dan pada akhirnya akan menghapuskan nafsu-nafsu jahat manusia

Dengan landasan eling-percaya-minuhu (ingat, percaya, dan taat) manusia akan dapat melakukan memaju hayuning bawana.

Bratasena harus mencari Kayu Gung Susuhing Angin yang letaknya di gunung Candramuka. Tanpa berpikir panjang, Bratasena langsung berangkat menuju puncak gunung Candramuka meskipun sangat berbahaya karena diserang dua raksasa, Rukmuka dan Rukmakala, yang merupakan jelmaan dari Hyang Indra dan Hyang Bayu. Setelah Bratasena berhasil menemukan Kayu Gung Susuhing Angin, ia segera pergi ke Laut Selatan untuk mencari Tirta Pawitra tetapi di tengah perjalanan dicegah oleh Anoman sehingga terjadi peperangan di Wana Sunyapringga dan dapat dimenangkan oleh Bratasena. Setelah sampai di Laut Selatan, Bratasena dililit oleh naga besar yang bernama Nagaraja. Akhirnya Nagaraja dapat dikalahkan oleh Bratasena dengan kuku Pancanakanya sehingga berhasillah ia dalam mencari ilmu kesempurnaan hidup.

\section{Hidup Rukun}

Prisip hidup rukun dapat terlihat dalam keluarga Pandawa. Dewi Kunthi sangat menyayangi anakanaknya, para Pandawa pun juga saling menyayangi dalam ikatan keluarga yang kuat.

\section{Jujur}

Perbuatan jujur pada dasarnya sangat diperlukan dalam berkomunikasi. Dalam cerita wayang 
purwa lakon Dewa Ruci terlihat bahwa Durna tidak jujur terhadap Bratasena. Durna menyuruh Bratasena mencari Kayu Gung Susuhing Angin dan Tirta Pawitra yang sebenarnya tidak ada, sedangkan Durna sendiri juga tidak mengetahui maknanya.

\section{Ikhlas dan Sepi Ing Pamrih}

Sikap ikhlas dimilki oleh Bratasena dalam mencari Kayu Gung Susuhing Angin dan Tirta Pawitra sehingga ia berhasil. Hal itu semua dilakukan karena kebersihan hati Bratsena dari hal-hal yang tidak ikhlas.

\section{Membentuk Watak Eling}

Sikap eling akan membentengi manusia untuk tidak berbuat jahat seperti yang selalu dilakukan oleh Kurawa. Mereka selalu menanamkan permusuhan terhadap Pandawa apalagi Sengkuni yang hidupnya hanya memikirkan masalah duniawi, tidak pernah eling kepada Tuhan.

\section{Taat Kepada Guru}

Durna merupakan sosok guru yang dianggap sejati oleh Bratasena. Segala perintahnya ditaati oleh Bratasena walaupun didalam hati Durna tertanam benih Kurawa yang jahat tetapi secara tersirat sebenarnya Durna telah mengajarkan motivasi mandiri kepada Bratasena dalam menuntut ilmu.

\section{Ora Ngaya dan Nrimo}

Ora ngaya menggambarkan sikap tidak memaksakan kehendak kepada orang lain. Sikap ini menggambarkan sikap hidup seseorang dalam bekerja. Orang yang hidupnya ora ngaya maka ia akan merasa tenang dan tidak terburuburudalam berusaha dan bekerja. Para Kurawa dalam hidupnya selalu ngaya ingin menghancurkan Pandawa karena mereka tidak nrima jika Pandawa menguasai kerajaan Astina sehingga segala laku Pandawa selalu diintai dan diikuti oleh Kurawa untuk dihancurkan. Sengkuni dan Kurawa selalu ngaya dan ora nrima jika Bratasena berhasil dalam menuntut ilmu.

\section{Teguh dalam Pendirian}

Orang yang mempunyai pendirianteguh akan menyebabkan tidak mudah terombang-ambing oleh keadaan. Ia memiliki idealisme yang tinggi sehingga tidak mudah dipengaruhi oleh orang lain. Orang yang teguh dalam pendirian adalah orang yang yakin bahwa idealismenya itu benar. Sedangkan orang yang tetap mempertahankan pendiriannya tetapi berada pada posisi yang salah maka orang tersebut tidak bisa dikategorikan sebagai orang yang berpendirian teguh tetapi sebagai orang yang kaku. Orangorang yang kaku dalam tokoh wayang purwa lakon Dwa Ruci dimainkan oleh para Kurawa. Sedangkan orang yang sangat terkenal dengan pendirian yang teguh adalah Bratasena.

Keteguhan hati Bratasena bisa dilihat dari cara berjalannya yang selalu lurus dan tidak pernah berbelok, berhias rambut terurai berkancing sanggul garuda membelakang dengan terhias yang melambangkan bahwa Bratasena tidak samar kepada Dewa dan jiwanya sendiri.

Keteguhan pendirian Bratasena terlihat ketika ia tetap memutuskan untuk terus berusaha mencari Kayu Gung Susauhing Angin dan Tirta Pawitra meskipun banyak sekali godaannya.

Setelah Bratasena berhasil menemukan Kayu Gung Susauhing Angin, ia kemudian mencari Tirta Pawitra di Laut Selatan. Ketika sampai di tepi Laut Selatan, Bratasena sedikit merasa takut menghadapi kondisi lautan yang bisa membahayakan dirinya, tetapi karena keteguhan pendiriannya, ia tetap masuk ke Laut Selatan.

Akhirnya Bratasena menemukan Tirta Pawitra dan mencapai derajat manunggaling kawula Gusti berkat keteguhan pendiriannya. Keadaan demikian digambarkan dalm pupuh Dhandhanggula (dalam Endraswara, 2003: 82) sebagai berikut:

Kamisayan ingkang makripati, den kaasta pamantenging cipta, rupa ingkang sabenere, sinenger bawaneku, urip datan ana anguripi, datan ana rumangsa, ing kahananipun, uwis ana ing sarira, tuhu tunggal sasana lawan sireki, tan kena pinisaha. Dipunweruh sangkanira uni, tunggal sawang kartining bawana, pandulu lan pamyarsane, wis ana ing siresku, panduluning sukma sejati, pan datan mawa netra, pamyasarnipun iya datan lawan karna, netranira karnanira kang kinardi, iya aneng sira.

Maksudnya pupuh di atas adalah bahwa manusia telah mencapai tingkat makrifat. Ia akan melihat kebenaran sejati. Disitulah manusia baru bisa menyatu dengan Sang Khalik yang tidak dapat dipisahkan. Maka, ketahuilah asal-usul manusia sebenarnya dapat dibaca pada diri manusia juga. Namun, cara melihat tidak dengan pancaindera yang tampak.

Keadaan ini telah dialami oleh Bratsena karena keteguhan pendiriannya ketika berada dalam diri Dewa Ruci. Ia menemukan jati dirinya dan lebih percaya diri karena telah mengetahui hakikat hidup serta semakin mantaplah pendiriannya. 


\section{Sikap Hormat}

Sikap hormat sangat diperlukan dalam kehidupan terutama dalam berinteraksi karena manusia merupakan makhluk sosial. Implikasi sikap hormat akan terkait dengan budi pekerti yang menyangkut unggah-ungguh dan tatakrama terutama dalam budaya Jawa. Hubungan antara anak-orang tua, murid-guru, sesama saudara secara tidak langsung juga akan mencerminkan aplikasi sikap hormat.

Bratasena selalu bersikap hormat kepada Dewa Ruci, Durna, Dewi Kunthi, dan saudarasaudaranya. Sikap hormat dapat diwujudkan dalam penggunaan bahasa yang menggunakan bahasa krama dan hal tersebut dilakukan oleh Bratasena terhadap Dewa Ruci.

\section{Yang Benar dan Tulus Pasti Menang}

Dengan kata lain, tindakan yang jelek dapat dikalahkan oleh ketulusan beribadah dan kuatnya usaha menuju kebajikan. Seperti diceritakan ketika Bratasena berhasil membunuh dua raksasa yang ternyata jelmaan dari Hyang Indro dan Hyang Bayu, kemudian dia diberi hadiah sebuah cincin yang bernama "Sesutya Mustika Manik Candrama". Cincin itu adalah ikatan untuk mendekatkan diri pada Tuhan. Dengan memakai cincin itu, Bratasena bisa berjalan di atas angin.

\section{Penutup}

Wayang merupakan kebudayaan daerah Indonesia yang bisa memperkaya kebudayaan nasional Indonesia. Selain itu, wayang juga merupakan sarana pendidikan baik moral maupun agama, sarana hiburan sosial, sarana mencari nafkah dan sebagai refleksi nilai dan estetis. Sebagai sarana pendidikan, wayang dapat menawarkan nilai dan ajaran yang bisa dicontoh oleh penonton. Selama ini pertunjukan wayang dibuat sedemikian rupa dengan berbagai inovasi. Salah satu bentuk dari inovasi itu adalah pertunjukan wayang purwa lakon Dewa Ruci dengan dalang Ki Manteb Soedharsono dalam kemasan VCD dengan durasi satu jam dalam bahasa Jawa dan disertai dengan teks bahasa Indonesia.

Performance pertunjukan wayang selalu dimodifikasi dengan berbagai inovasi karena untuk menghindari kejenuhan dari para penonton terutama generasi muda yang sudah tidak tertarik lagi dengan sastra Jawa khususnya wayang. Dengan modifikasi yang inovatif itu diharapkan penonton terutama generasi muda semakin tertarik dengan pertunjukan wayang sehingga nilai-nilai dan ajaran-ajarannya bisa dijadikan contoh dalam hidup.

Selama ini generasi muda banyak yang terjerumus dan terkontaminasi dengan kebudayaan barat yang tidak sesuai dengan kebudayaan Indonesia dan mereka banyak yang sudah tertarik budaya sendiri yang penuh dengan nilai-nilai terutama wayang yang memuat nilainilai adiluhung. Siswa yang tertarik dengan modifikasi pertunjukan wayang yang inovatif (misalnya pertunjukan wayang purwa dengan lakon Dewa Ruci dengan dalang Ki Manteb Sudarsono) dapat mengambil nilai-nilai edukatif yang terdapat dalam cerita wayang tersebut sehingga bisa diimplementasikan dalam kehidupan dan terwujudlah tujuan pendidikan nasional sesuai yang diharapkan dalam UU Sisdiknas nomor 20 tahun 2003.

Kebanyakan orang berpendapat bahwa orientasi pembelajaran ideal adalah orientasi pembelajaran yang paling dekat dengan siswa, materi yang sesuai dengan budaya sendiri misalnya wayang yang ceritanya tidak pernah luntur oleh perkembangan zaman. Wayang dapat dijadikan sebagai media pembelajaran misalnya dengan pemutaran film lewat VCD. Dengan adanya pemutaran film lewat VCD akan lebih mudah dicontoh oleh siswa karena sesuai dengan teori psikologi yaitu behaviorisme yang menyatakan bahwa perkembangan anak dipengaruhi oleh lingkungan sekitarnya.

Tulisan ini diharapkan bermanfaat untuk semua orang dengan berbagai latar belakang/posisi, apakah mereka beposisi sebagai siswa, orang tua, masyarakat, guru maupun pemerintah. Siswa dapat belajar dari Bratasena dalam menuntut ilmu dan mengimplementasikan nilai dan edukatif dalam cerita wayang purwa lakon Dewa Ruci dalam kehidupan sehingga dapat menjadi orang yang sesuai dengan tujuan pendidikan nasional (UU Sisdiknas nomor 20 tahun 2003), orang tua dapat belajar dari Dewi Kunthi yang selalu demokratis, tabah dan sabar dalam menghadapi kehidupan, ia membiarkan anaknya memilih jalan hidup sesuai dengan kompetensi yang dimiliki anak tersebut; masyarakat juga dapat mengimplementasikan nilai-nilai edukatif dalam cerita wayang purwa lakon Dewa Ruci, guru dapat melihat sosok Durna dalam mendidik muridnya (Bima); pemerintah dapat memberikan perhatian yang intens terhadap wayang purwa karena ia merupakan kebudayaan daerah yang bisa memperkaya kebudayaan nasional Indonesia.

Di era globalisasi dengan semakin menjamurnya budaya dan saling kontak antarnegara akan 
menimbulkan kompetisi dengan sastra asing yang semakin luas penyebarannya. Oleh sebab itu, sastra daerah dan Indonesia harus mampu menunjukkan jati diri dan eksistensi bangsa di mata dunia, serta harus mampu menjadi media transformasi nilai-nilai budaya modern yang berkembang selaras dengan ilmu pengetahuan, teknologi, dan seni (Ipteks).

Cerita Dewa Ruci memberikan kontribusi terhadap sistem pendidikan kita saat ini. Selama ini pendidikan di Indonesia hanya transfer of knowledge dari guru kepada murid, tanpa dilandasi dengan pemahaman makna dan pengetahuan itu sendiri. Kebijakan-kebijakan yang telah digulirkan pemerintah telah banyak mengurangi independensi sekolah, guru, dan murid untuk berkreasi dan berinovasi sehingga transformasi pendidikan di Indonesia kebanyakan menghasilkan out put yang verbalistik dan individualistik. Sistem pendidikan kita bisa meniru dari kemandirian seorang murid yang bernama Bratasena dalam mencari ilmu untuk meraih cita-cita dengan motivasi dan petunjuk dari guru.

\section{DAFTAR PUSTAKA}

Ardhie, Maria. 2003. Pengembangan Kepribadian Manusia Indonesia. Makalah PKMM FKIP UNS.

Atmazaki. 1990. Ilmu Sastra, Teori dan Terapan. Padang: Angkasa Raya.

Endraswara, Suwardi. 2003. Budi Pekerti dalam Budaya Jawa. Yogyakarta: PT Hanindita Graha Widya.

Fananie, Zainudin. 1982. Telaah Sastra. Surakarta: Muhammadiyah University Press.

Haryono, Bagus dan Mahendra Wijaya. 2001. "Minat Menonton Wayang purwa dan Sosialisasi Nilai bagi Remaja Pedesaan"Jurnal Ilmu Sosial dan Ilmu Politik.

Haz. 2004. Gaung Sastra Jawa Perlu ditumbuhkan kembali di Sekolah. http://www.jatim.go.id/news.php?id=2369dant=082259, diakses tanggal 4 November 2004.

Lord, Albert B. 1976. The Singer of Tales. Yogyakarta: Tiara Wacana.

Manhitu, Yohanes. 2010. Sastra Lisan pada Masa Kini: Sekilas Pandang. http://ymanhitu.blogspot.com/2010/02/sastra-lisan-pada-masa-kini-sekilas.html. (Diakses tanggal 10 Juni 2010).

Ong, Wolker J. 1982. Intersaces of The Word Studies in The Evolution of Conciosness and Culture. Itacha: Cornel University Press.

Rahayu Supanggah. 2002. "Sistem Pendidikan Dewa Ruci: Sebuah Tawaran". Jurnal Pengkajian dan Penciptaan Seni.

Sayuti, Suminto. 2001. "Pengajaran Sastra sebagai Media Transformasi Edukatif, Kultural, dan Keluhuran Budi Manusia". Jurnal Bahasa dan Sastra Indonesia Menuju Peran Transformasi Sosial Budaya Abad XXI. 513-518.

Sudaryanto. 2003. Menghumanisasikan Pendidikan Lewat Sastra. Makalah Studi Banding HIMA PBSI UNY dengan HIMPROBSI FKIP UNS.

Triyogo, Yohanes Brefeur Rahno dan Kuntara Wiryamartana. 2001. "Hubungan Intertekstual dalam Banjaran Gathutkaca Karya Ki Nartosabdo". Sosiohimanika. 14 (2), 323 - 334.

Wayang purwa jadi Warisan Budaya Dunia. 2004. April. Solopos. 8

2003. Undang-Undang Republik Indonesia Nomor 20 Tahun 2003 tentang SISDIKNAS. Bandung: Citra Umbara. 